\title{
Acetate regulates milk fat synthesis through the mammalian target of rapamycin/eukaryotic initiation factor 4E signaling pathway in bovine mammary epithelial cells
}

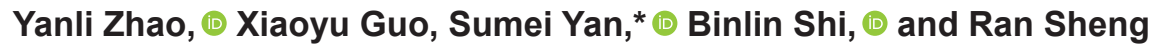 \\ College of Animal Science, Inner Mongolia Key Laboratory of Animal Nutrition and Feed Science, Inner Mongolia Agricultural University, Hohhot \\ 010018, China
}

\begin{abstract}
Acetate is a short-chain fatty acid (SFA) that is the major substrate for de novo fatty acid synthesis. The mammalian target of rapamycin/eukaryotic initiation factor $4 \mathrm{E}$ (mTOR/eIF4E) signaling pathway is involved in fat synthesis. However, the effect and mechanism of acetate on fatty acid synthesis by the $\mathrm{mTOR} / \mathrm{eIF} 4 \mathrm{E}$ signaling pathway is unclear in bovine mammary epithelial cells (BMECs). The objectives of this study were to investigate the effect of acetate on cell viability, triacylglycerol (TG), and mRNA expression of the genes related to lipid synthesis. The mechanism of acetate regulation milk fat synthesis through the mTOR/eIF4E signaling pathway was assessed by blocking the mTOR signaling pathway and silencing eIF $4 E$ in BMECs. Third-passage BMECs were allocated to 6 treatments including $0,4,6,8,10$, and 12 $\mathrm{m} M$ acetate to evaluate the effect of acetate on lipid synthesis; the optimum concentration in the first study was selected for the subsequent study. Subsequently, cells were randomly allocated to 4 treatments, 1 control group and 3 treated groups, consisting of acetate $(6$ $\mathrm{m} M)$, rapamycin $(100 \mathrm{n} M)$, and acetate + rapamycin to test the role of mTOR signaling pathway response to acetate in milk lipid synthesis. Finally, eIF4E was silenced by small interfering RNA (siRNA) to detect the role of eIF4E in milk lipid synthesis. Treatments included control, eIF4E siRNA, acetate $(6 \mathrm{mM})$, and acetate+ eIF4E siRNA. Results showed that acetate increased TG accumulation and the relative expression of fatty acid synthase $(F A S N)$, acetyl-coenzyme A carboxylase $\alpha(A C A C A)$, fatty acid-binding protein 3 (FABP3), sterol regulatory element binding protein 1 (SREBP1), peroxisome proliferator-activated receptor gamma (PPARG), mTOR, eIF4E, P70 ribosomal
\end{abstract}

Received January 22, 2020.

Accepted August 31, 2020.

*Corresponding author: yansmimau@163.com protein S6 kinase-1 (S6K1), and 4E-binding protein-1 $(4 E B P 1)$ in a dose-dependent manner. Rapamycin effectively inhibited the positive effect of acetate on the relative expression of $m T O R$, eIF $4 E, S 6 K 1,4 E B P 1$, $F A S N, \quad A C A C A, \quad F A B P 3$, stearoyl-CoA desaturase (SCD1), SREBP1, and PPARG. The upregulation of acetate on the relative expressions of FASN, ACACA, $S C D 1$, and $S R E B P 1$ was suppressed when eIF4E was knocked down. It suggested that acetate regulated milk fat synthesis through mTOR/eIF4E signaling pathway in BMECs.

Key words: acetate, mammalian target of rapamycin, eukaryotic initiation factor $4 \mathrm{E}$, milk fat synthesis, bovine mammary epithelial cell

\section{INTRODUCTION}

Milk fat is the major energy component of milk, and regulation of its synthesis is of interest because milk fat is important for production, quality, and flavor aspects of milk. In cows, about one-half of fatty acids (FA) come from de novo FA synthesis, with acetate and $\beta$-hydroxybutyrate as the primary precursors (Bauman and Griinari, 2003). The other half of milk FA are preformed FA taken up from circulation by the mammary gland (Bauman and Griinari, 2003). Acetate is the main short-chain FA, and it dose-dependently stimulates milk fat synthesis by increasing de novo FA synthesis in lactating dairy cows (Urrutia and Harvatine, 2017).

Some research has indicated that acetate affects milk fat synthesis and lipogenic gene expression in the bovine mammary gland (Maxin et al., 2011; Jacobs et al., 2013), but the mechanism for acetate to regulate milk fat synthesis in the bovine mammary gland and its regulatory pathways are still not well understood. The mammalian target of rapamycin (mTOR) is a serine/threonine kinase that plays an important role in cell growth (Burgos et al., 2010); mTOR exists in 2 complexes: mTOR complex 1 (mTORC1) and 2 (mTORC2; Guertin and Sabatini, 2007). Whereas 
mTORC1 integrates growth factors, energy status, oxygen, and amino acids to regulate many processes involved in the promotion of cell growth and metabolism, mTORC2 is generally regarded as a responder to growth factor input and a regulator of cell metabolism (Oh and Jacinto, 2011). In addition to regulating the production of proteins, mTOR also controls the lipid metabolism (Lamming and Sabatini, 2013). The mTORC1 complex acts through the sterol regulatory element-binding protein 1/2 (SREBP1/2) transcription factors that control the expression of numerous genes involved in FA synthesis (Laplante and Sabatini, 2012). Rapamycin, a specific mTORC1 inhibitor, blocks the expression of SREBP1 target genes fatty acid synthase $(F A S N)$, acetyl-coenzyme A carboxylase $\alpha(A C A C A)$, and stearoyl-CoA desaturase 1 (SCD1), indicating a role for mTORC1 in fatty acid biosynthesis (Anderson et al., 2007; Luyimbazi et al., 2010). Peroxisome proliferator-activated receptor gamma $(P P A R G)$ activates fatty acid uptake, synthesis, esterification, and storage in the newly synthesized adipocytes in the mouse model, and rapamycin inhibits the activation of $P P A R G$ (Soliman, 2011). These results indicated that PPARG plays another important role in mTOR signaling pathway in regulating milk fat synthesis. In addition, eukaryotic translation initiation factor $4 \mathrm{E}$ (eIF4E) is the key regulator of mTOR signaling pathway, and eIF4E small interfering RNA (siRNA) decreases protein expression of $S C D 1$ and $S R E B P 1$, indicating that $S C D 1$ and $S R E B P 1$ may be regulated through the mTOR/eIF4E pathway in a breast cancer cell line (Luyimbazi et al., 2010). Although much is known about the dependence of mTOR/eIF4E on AA (Efeyan et al., 2012), less is known about the ability of mTOR to respond to the presence of other nutrients essential for cell growth or milk fat synthesis such as acetate.

We hypothesized that acetate regulates fat synthesis through mTOR/eIF4E signaling pathway, and the effect of mTOR/eIF4E signaling pathway on milk fat synthesis in the bovine mammary gland may occur via PPARG and SREBP1. Therefore, the specific objective of this study was to establish the role of $\mathrm{mTOR} / \mathrm{eIF} 4 \mathrm{E}$ signaling in mediating the effects of acetate availability on fat synthesis in bovine mammary epithelia cells (BMEC).

\section{MATERIAL AND METHODS}

\section{Isolation and culture of BMEC}

Primary cells were isolated from the mammary glands of 6 Holstein dairy cows at a local abattoir. The BMEC were obtained as described by Sheng et al. (2016). Cells were cultured in the Dulbecco's modified Eagle's medium (DMEM)/F12 supplemented with $10 \%$ fetal bovine serum (FBS; Gibco, Grand Island, NY), 0.5\% insulin, $4 \mu \mathrm{g} / \mathrm{mL}$ prolactin, $1 \mu \mathrm{g} / \mathrm{mL}$ hydrocortisone, 100 $\mathrm{U} / \mathrm{mL}$ penicillin, and $100 \mu \mathrm{g} / \mathrm{mL}$ streptomycin (Gibco) at $37^{\circ} \mathrm{C}$ in a humidified atmosphere of $5 \% \mathrm{CO}_{2}$. When cells reached $90 \%$ confluence, $0.25 \%$ trypsin was added to separate epithelial cells from fibroblasts according to their different sensitivities to trypsin (Figure 1).

\section{Experimental Design}

For all treatments, FBS in the culture solution was replaced with FA-free BSA $(1 \mathrm{~g} / \mathrm{L})$. At approximately 80 to $90 \%$ confluence, BMEC were incubated in the
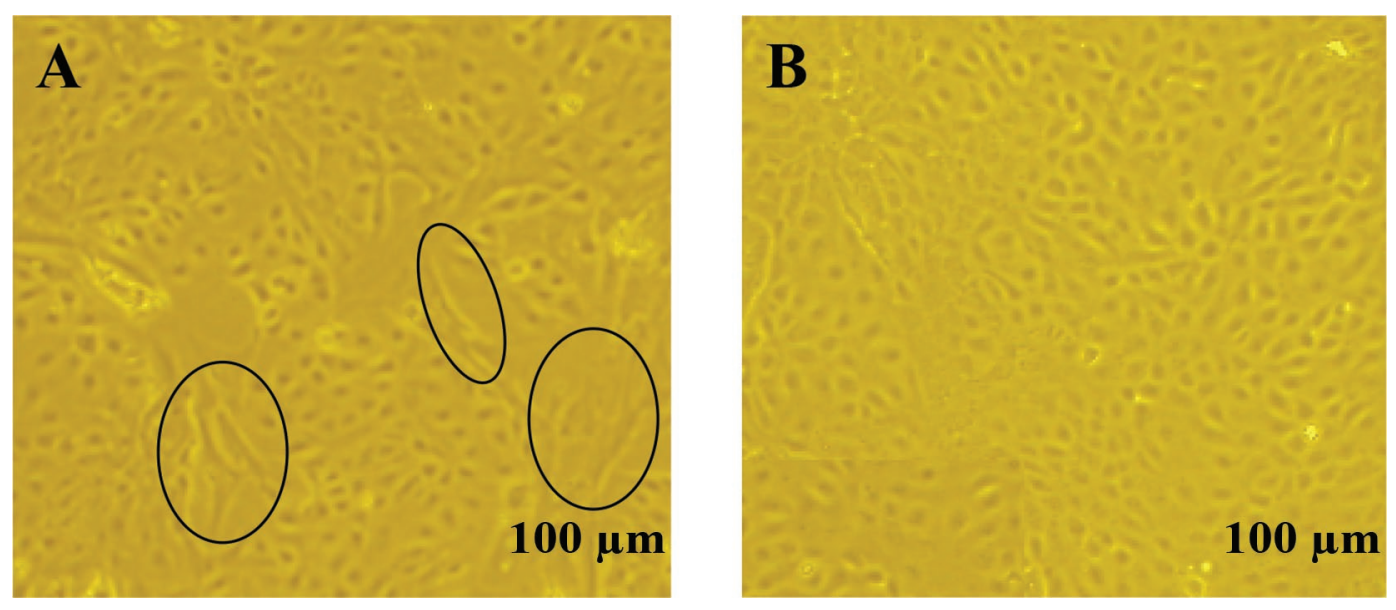

Figure 1. Microscope images of primer mammary epithelial cells (A) and purified cells (B). The scale bar is $100 \mu \mathrm{m}$. The cells included small numbers of fibroblasts (circled) in primer cells (A), and few fibroblasts were observed after purification (B). 
experimental medium at $37^{\circ} \mathrm{C}$ and $5 \% \mathrm{CO}_{2}$. This study included 3 experiments. The first experiment included 6 groups of cells cultured in DMEM/F12 medium with $0,4,6,8,10$, or $12 \mathrm{~m} M$ acetate sodium (SigmaAldrich, Munich, Germany) for $48 \mathrm{~h}$; acetate sodium at $0 \mathrm{~m} M$ was the control group. The optimum acetate concentration for the TG synthesis and gene expression was selected for the subsequent research. A completely random design was used to conduct the second experiment. The 4 treatments were (1) control, (2) rapamycin $(\mathbf{R})$ : cells were cultured in DMEM/F12 with $100 \mathrm{n} M$ rapamycin for $48 \mathrm{~h}$; (3) acetate (A): cells were cultured in DMEM/F12 with $6 \mathrm{~m} M$ acetate for $48 \mathrm{~h}$; (4) rapamycin + acetate $(\mathbf{R}+\mathbf{A})$ : cells were cultured in DMEM/F12 with acetate and $100 \mathrm{n} M$ rapamycin for 48 h. The third experiment was conducted as follows: the BMEC were randomly allocated to 4 treatments including (1) control: cells were cultured in DMEM/F12 for $24 \mathrm{~h}$, and then in fresh DMEM/F12 for another $48 \mathrm{~h}$; (2) acetate: cells were cultured in DMEM/F12 for 24 $\mathrm{h}$ and then cultured in medium with $6 \mathrm{~m} M$ acetate for $48 \mathrm{~h}$; (3) eIF4E siRNA: cells were cultured in DMEM/ F12 with eIF4E siRNA for $24 \mathrm{~h}$ and then in DMEM/ F12 for another $48 \mathrm{~h}$; (4) acetate+eIF4E siRNA: cells were cultured in DMEM/F12 with eIF4E siRNA for 24 $\mathrm{h}$ and then cultured with acetate for another $48 \mathrm{~h}$. Cells were treated with experimental media at $37^{\circ} \mathrm{C}$ and $5 \%$ $\mathrm{CO}_{2}$. Each treatment was performed in sextuplicates.

\section{Small Interfering RNA Transfection}

The eIF4E siRNA and negative control siRNA were provided by Hanbio (Shanghai, China). The eIF4E siRNA gene (GenBank NM_174310.3) sequences were custom-ordered duplexes as follows: eIF4E siRNA1 (sense, 5'-CAGAGACGAAGTGACCTCGATCGTT-3'), eIF4E-siRNA2 (sense, 5'-GGGTATACAAGGAAAGGTTAG-3'), and eIF4E-siRNA3 (sense, 5'-GGCAAGCAAACCTTCGATTGA-3'). Then, BMEC were either transfected with the eIF4E-siRNA or negative control RNA-oligonucleotides using Lipofectamine 3000 (Invitrogen, Carlsbad, CA) according to the manufacturer's protocol. Briefly, BMEC (30 to $50 \%$ confluent) were grown in 6-well plates overnight, and then transfected with siRNA and Lipofectamine 3000 for $24 \mathrm{~h}$. The cells were then collected for verification of eIF4E knockdown by quantitative real-time (QRT)-PCR.

\section{Cell Viability Assay}

Viability of cells was determined by the methylthiazolyl tetrazolium (MTT) assay, which consisted of plating $1 \times 10^{4}$ cells in every well of a 96 -well plate. Briefly, after incubation, $20 \mu \mathrm{L}$ of $5 \mathrm{mg} / \mathrm{mL}$ MTT was added to each well and incubated for $4 \mathrm{~h}$ at $37^{\circ} \mathrm{C}$. The resulting formazan crystals were then dissolved in 100 $\mu \mathrm{L}$ of dimethyl sulfoxide. The absorbance of each well was read at $490 \mathrm{~nm}$ using a microplate reader (BioTek, Winooski, VT). The results were expressed as percentage of control values.

\section{Oil Red O Staining and Assay}

Intracellular triglyceride accumulation was measured by Oil Red $\mathrm{O}$ staining according to the method of Ramirez-Zacarias et al. (1992). The Oil Red O method was carried out to detect lipid droplet staining in cells. Briefly, cells were plated in 24-well plates at $5 \times 10^{4}$ cells/well, washed with PBS after incubation, and then fixed with $4 \%$ paraformaldehyde for $1 \mathrm{~h}$. Fixed cells were washed with PBS and stained with $0.5 \mathrm{~mL}$ of Oil Red $\mathrm{O}$ for $2 \mathrm{~h}$. Cells were then rinsed 3 times with PBS. For quantification, cells were incubated with $0.3 \mathrm{~mL}$ of isopropanol for 20 min to extract Oil Red O staining, and optical density (OD) was measured at $510 \mathrm{~nm}$ by a microplate reader (BioTek).

\section{RNA Extraction and Real-Time PCR}

Cells were plated in 6 -well plates at $1 \times 10^{5}$ cells/well in lactogenic medium. Total RNA was collected using Trizol (Takara, Shanghai, China). Briefly, cell lysate was collected using $1 \mathrm{~mL}$ RNAiso plus (Takara). The lysate was deproteinized by $1 \mathrm{~mL}$ chloroform, and the supernatant was added into equal volume isopropanol to deposited RNA. The RNA pellet was washed with 1 $\mathrm{mL}$ alcohol and then dissolved in RNA-free $\mathrm{H}_{2} \mathrm{O}$. The RNA quality was assessed from the $\mathrm{OD}_{260} / \mathrm{OD}_{280}$ ratio and agarose gel electrophoresis.

Complementary DNA was generated for real-time PCR in a $10-\mu \mathrm{L}$ volume using Prime Script RT Master Mix (Takara). Real-time PCR reactions were carried out in $20-\mu \mathrm{L}$ reactions containing $10 \mu \mathrm{L}$ of $2 \times \mathrm{SYBR}$ Premix Ex Taq II, $2 \mu \mathrm{L}$ of cDNA, $0.4 \mu \mathrm{L}$ each of 10 $\mu M$ forward and reverse primers, and $7.2 \mu \mathrm{L}$ of RNasefree water. Glyceraldehyde phosphate dehydrogenase $(G A P D H)$ and $A C T B$ were used as the internal control. Primers used are presented in Table 1. Reactions were performed in a MxPro-Mx3000P (Agilent Technologies, Santa Clara, CA). The real-time PCR involved an initial denaturing step of $95^{\circ} \mathrm{C}$ for $30 \mathrm{~s}$ followed by 40 cycles of $95^{\circ} \mathrm{C}$ for $30 \mathrm{~s}$ (denaturation), $60^{\circ} \mathrm{C}$ for $30 \mathrm{~s}$ (annealing), and $72^{\circ} \mathrm{C}$ for $20 \mathrm{~s}$ (extension). Quality and specificity of PCR products were assessed by melt curve analysis and subsequent agarose gel electrophoresis. The quan- 
Table 1. Primer sequences (F, forward; $\mathrm{R}$, reverse)

\begin{tabular}{|c|c|c|c|}
\hline Gene $^{1}$ & GenBank no. & Primer sequences $\left(5^{\prime}-3^{\prime}\right)$ & $\begin{array}{l}\text { Length } \\
\text { (bp) }\end{array}$ \\
\hline$G A P D H$ & XM_001252479 & $\begin{array}{l}\text { F: GGGTCATCATCTCTGCACCT } \\
\text { R: GGTCATAAGTCCCTCCACGA }\end{array}$ & 177 \\
\hline$A C T B$ & NM_173979.3 & $\begin{array}{l}\text { F: AACTCCATCATGAAGTGTGACG } \\
\text { R: GATCCACATCTGCTGGAAGG }\end{array}$ & 234 \\
\hline$F A S N$ & NM_001012669 & $\begin{array}{l}\text { F: AGGACCTCGTGAAGGCTGTGA } \\
\text { R: CCAAGGTCTGAAAGCGAGCTG }\end{array}$ & 85 \\
\hline$A C A C A$ & AJ132890 & $\begin{array}{l}\text { F: CATCTTGTCCGAAACGTCGAT } \\
\text { R: CCCTTCGAACATACACCTCCA }\end{array}$ & 101 \\
\hline$S C D 1$ & AY241933 & $\begin{array}{l}\text { F: TCCTGTTGTTGTGCTTCATCC } \\
\text { R: GGCATAACGGAATAAGGTGGC }\end{array}$ & 101 \\
\hline FABPЗ & DN518905 & $\begin{array}{l}\text { F: GAACTCGACTCCCAGCTTGAA } \\
\text { R: AAGCCTACCACAATCATCGAAG }\end{array}$ & 102 \\
\hline$L P L$ & BC118091 & $\begin{array}{l}\text { F: ACACAGCTGAGGACACTTGCC } \\
\text { R: GCCATGGATCACCACAAAGG }\end{array}$ & 101 \\
\hline$P P A R G$ & NM_181024 & $\begin{array}{l}\text { F: CCAAATATCGGTGGGAGTCG } \\
\text { R: ACAGCGAAGGGCTCACTCTC }\end{array}$ & 101 \\
\hline$S R E B P 1$ & NM_001113302 & $\begin{array}{l}\text { F: CTGACGACCGTGAAAACAGA } \\
\text { R: AGACGGCAGATTTATTCAACTT }\end{array}$ & 334 \\
\hline$m T O R$ & XM_001788228 & $\begin{array}{l}\text { F: TGAACTGGAGGCTGATGGACAC } \\
\text { R: TGACTGGCCAGCAGAGTAGGAA }\end{array}$ & 83 \\
\hline $4 E B P 1$ & BC120290 & $\begin{array}{l}\text { F: GGCAGGCGGTGAAGAGTC } \\
\text { R: CCTGGGCTGCGGGAT }\end{array}$ & 302 \\
\hline$S 6 K 1$ & DN544771 & $\begin{array}{l}\text { F: CAAGCTTGCATGCTAATTTGTCC } \\
\text { R: TTGAGTCCTGATCATGTCGAAGA }\end{array}$ & 101 \\
\hline$e I F 4 E$ & NM_174310.3 & $\begin{array}{l}\text { F: GAAGACTTTTGGGCTCTGTAC } \\
\text { R: CAGCTCCACATACATCATCAC }\end{array}$ & 82 \\
\hline
\end{tabular}

${ }^{1} F A S N=$ fatty acid synthase; $A C A C A=$ acetyl-CoA carboxylase; $S C D 1=$ stearoyl-CoA desaturase; $F A B P 3=$ fatty acid-binding protein $3 ; L P L=$ lipoprotein lipase; $P P A R G=$ peroxisome proliferator-activated receptor gamma; $S R E B P 1=$ sterol regulatory element binding protein $1 ; m T O R=$ mammalian target of rapamycin; $4 E B P 1=4$ E-binding protein $1 ; S 6 K 1=$ ribosomal protein $S 6$ kinase $\beta-1 ;$ eIF $4 E=$ eukaryotic translation initiation factor $4 \mathrm{E}$.

titative real-time PCR data were calculated by $2^{-\Delta \Delta \mathrm{CT}}$ method (Livak and Schmittgen, 2001).

\section{Statistical Analysis}

Data were analyzed using variance statistics (GLM) followed by the Duncan's test for post hoc multiple comparisons of treatment means using SAS software (SAS Institute Inc., Cary, NC). The fixed effect was treatment and random effect was replicate in the statistic model. In addition, we conducted a regression analysis using SAS in experiment 1. Significance was considered at $P<0.05$. Trends were discussed at 0.05 $<P<0.10$ unless otherwise stated.

\section{RESULTS}

\section{Effect of Acetate on Milk Fat Synthesis in BMEC}

Cell relative growth rate (RGR) was quadratically $(P<0.05)$ increased when acetate concentration was increased from 4 to $10 \mathrm{~m} M$ acetate; however, RGR was decreased in $12 \mathrm{mM}$ acetate. The RGR was higher with 4 to $8 \mathrm{~m} M$ acetate and peaked at $120 \%$ of control when the concentration of acetate was $4 \mathrm{mM}$. However, 12 $\mathrm{m} M$ acetate decreased the RGR compared with other groups (Table 2). The concentration of TG showed a linear and quadratic response to increasing acetate concentration, and was greater with 8 to $12 \mathrm{mM}$ acetate $(P$ $<0.05$; Table 2)

Table 2. Effect of acetate on relative growth rate (RGR) and triacylglycerol (TG, measured as optical density, OD) content in bovine mammary epithelial cells

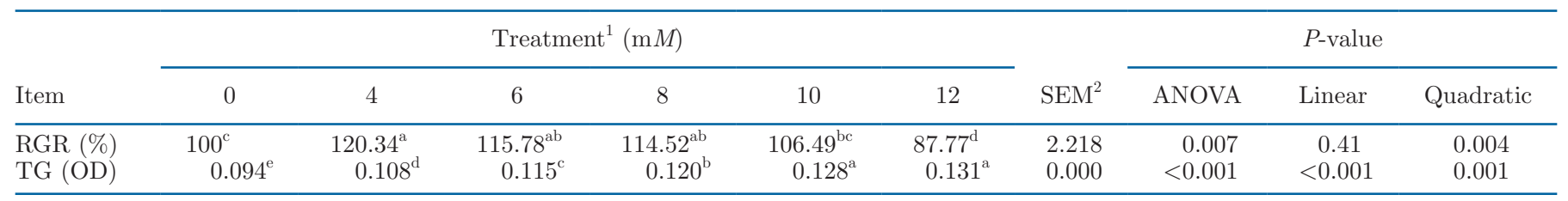

${ }^{\mathrm{a} e} \mathrm{e}$ Means in a row without a common letter differ, $P<0.05$.

${ }^{1}$ Treatments included 6 concentrations of acetate: $0,4,6,8,10$, and $12 \mathrm{~m} M$ added to culture medium for $48 \mathrm{~h}$. 
Table 3. Effect of acetate on the expression of genes involved in milk fat synthesis and mammalian target of rapamycin (mTOR) signaling pathway in bovine mammary epithelial cells

\begin{tabular}{|c|c|c|c|c|c|c|c|c|c|c|}
\hline \multirow[b]{2}{*}{ Gene } & \multicolumn{6}{|c|}{ Treatment $^{1}(\mathrm{~m} M)$} & \multirow[b]{2}{*}{ SEM } & \multicolumn{3}{|c|}{$P$-value } \\
\hline & 0 & 4 & 6 & 8 & 10 & 12 & & ANOVA & Linear & Quadratic \\
\hline$F A S N$ & $1.00^{\mathrm{c}}$ & $1.30^{\mathrm{b}}$ & $1.49^{\mathrm{b}}$ & $1.55^{\mathrm{ab}}$ & $1.67^{\mathrm{ab}}$ & $1.78^{\mathrm{a}}$ & 0.017 & $<0.0001$ & $<0.0001$ & 0.001 \\
\hline$A C A C A$ & $1.00^{\mathrm{c}}$ & $1.33^{\mathrm{b}}$ & $1.39^{\mathrm{b}}$ & $1.45^{\mathrm{ab}}$ & $1.50^{\mathrm{a}}$ & $1.62^{\mathrm{a}}$ & 0.024 & 0.013 & $<0.0001$ & 0.001 \\
\hline$S C D 1$ & 1.00 & 1.20 & 1.13 & 1.13 & 1.12 & 1.11 & 0.027 & 0.32 & 0.45 & 0.19 \\
\hline FABP3 & $1.00^{\mathrm{d}}$ & $1.88^{\mathrm{c}}$ & $2.24^{\mathrm{c}}$ & $2.52^{\mathrm{b}}$ & $2.91^{\mathrm{ab}}$ & $3.15^{\mathrm{a}}$ & 0.034 & $<0.0001$ & $<0.0001$ & 0.004 \\
\hline$L P L$ & 1.00 & 0.97 & 0.98 & 1.01 & 0.97 & 1.0 & 0.008 & 0.99 & 0.43 & 0.52 \\
\hline$m T O R$ & $1.0^{\mathrm{c}}$ & $1.67^{\mathrm{a}}$ & $1.43^{\mathrm{b}}$ & $1.11^{\mathrm{bc}}$ & $0.93^{\mathrm{c}}$ & $0.86^{\mathrm{d}}$ & 0.262 & $<0.0001$ & 0.41 & 0.034 \\
\hline eIF4E & $1.0^{\mathrm{c}}$ & $2.12^{\mathrm{a}}$ & $1.98^{\mathrm{a}}$ & $1.65^{\mathrm{b}}$ & $1.43^{\mathrm{b}}$ & $1.38^{\mathrm{bc}}$ & 0.124 & $<0.0001$ & 0.098 & 0.003 \\
\hline $4 E B P 1$ & $1.0^{\mathrm{d}}$ & $1.25^{\mathrm{c}}$ & $1.70^{\mathrm{a}}$ & $1.55^{\mathrm{b}}$ & $1.50^{\mathrm{b}}$ & $1.26^{\mathrm{c}}$ & 0.076 & $<0.0001$ & 0.19 & 0.009 \\
\hline$S 6 K 1$ & $1.0^{\mathrm{c}}$ & $1.53^{\mathrm{a}}$ & $1.55^{\mathrm{a}}$ & $1.32^{\mathrm{ab}}$ & $1.18^{\mathrm{bc}}$ & $1.19^{\mathrm{bc}}$ & 0.343 & $<0.0001$ & 0.25 & 0.088 \\
\hline
\end{tabular}

${ }^{\mathrm{a}-\mathrm{d}}$ Means in a row without a common letter differ, $P<0.05$.

${ }^{1}$ Treatments included 6 concentrations of acetate: $0,4,6,8,10$, and $12 \mathrm{~m} M$ added to culture medium for $48 \mathrm{~h}$.

The relative expression of $F A S N, A C A C A$, fatty acidbinding protein 3 (FABP3), SREBP1, and PPARG were linearly and quadratically increased $(P<0.05)$ with increased acetate concentration (Table 3). Compared with control, acetate increased expression of FASN, ACACA, FABP3, SREBP1, and PPARG $(P<$ $0.05)$. Medium with 8 to $12 \mathrm{~m} M$ acetate had a greater effect on expression of FASN, ACACA, FABP3 (all $P$ $<0.05$ ), but expression of FASN and $A C A C A$ did not differ between 6 and $8 \mathrm{~m} M$. Expression of $S R E B P 1$ and PPARG was higher with 6 to $12 \mathrm{mM}$ acetate $(P$ $<0.05)$. Expression of $S C D 1$ and lipoprotein lipase $(L P L)$ did not respond to acetate treatment (Table 3 ). The addition of acetate significantly increased or tended to increase the relative expression of $m T O R$, eIF4E, 4EBP1 $(P<0.05)$, and S6K1 $(P=0.088)$ in a quadratically dose-dependent manner. Expression of $m T O R$ and $e I F 4 E$ were greater with 4 to $6 \mathrm{mM}$ acetate, and $4 E B P 1$ expression was greater in $6 \mathrm{~m} M$ acetate. Expression of S6K1 was greater in 4 to $8 \mathrm{~m} M$ acetate than in the other concentrations evaluated $(P<0.05)$.

\section{Effect of Rapamycin on Milk Fat Synthesis in BMEC}

Acetate increased RGR and TG, but $\mathrm{R}$ and $\mathrm{R}+\mathrm{A}$ significantly decreased RGR and TG $(P<0.05)$, and there was no difference between $\mathrm{R}$ and $\mathrm{R}+\mathrm{A}(P>0.05$; Table 4). The expression of mTOR, eIF4E, S6K1, and $4 E B P 1$ was higher in $\mathrm{A}(P<0.05$; Table 5$)$. Compared with control and $\mathrm{A}$, the $\mathrm{R}$ and $\mathrm{R}+\mathrm{A}$ treatments significantly downregulated abundance and there was no difference between $\mathrm{R}$ and $\mathrm{R}+\mathrm{A}(P>0.05)$. The mRNA expression of FASN, ACACA, FABP3, SCD1, PPARG, and SPEBP1 was similar to that of $m T O R$ in BMEC (Table 5). Treatments $\mathrm{A}$ and $\mathrm{R}$ did not affect mRNA expression of $L P L(P=0.63)$.

\section{Effect of elF4E Knockdown on Milk Fat Synthesis in BMEC}

Three independent eIF4E siRNA sequences led to marked knockdown of eIF4E expression. Compared with control siRNA, mRNA expression of eIF4E de-

Table 4. Effect of acetate and rapamycin on relative growth rate (RGR) and triacylglycerol (TG, measured as optical density, OD) content in bovine mammary epithelial cells

\begin{tabular}{|c|c|c|c|c|c|c|}
\hline \multirow[b]{2}{*}{ Item } & \multicolumn{4}{|c|}{ Treatment $^{1}$} & \multirow[b]{2}{*}{ SEM } & \multirow{2}{*}{$\begin{array}{c}\text { Overall } \\
\text { treatment } \\
P \text {-value }\end{array}$} \\
\hline & Control & $\mathrm{R}$ & A & $\mathrm{R}+\mathrm{A}$ & & \\
\hline $\begin{array}{l}\text { RGR (\%) } \\
\text { TG (OD) }\end{array}$ & $\begin{array}{c}100.0^{\mathrm{b}} \\
0.422^{\mathrm{b}}\end{array}$ & $\begin{array}{c}73.1^{\mathrm{c}} \\
0.373^{\mathrm{c}}\end{array}$ & $\begin{array}{c}107.2^{\mathrm{a}} \\
0.466^{\mathrm{a}}\end{array}$ & $\begin{array}{c}75.8^{\mathrm{c}} \\
0.350^{\mathrm{c}}\end{array}$ & $\begin{array}{l}0.563 \\
0.002\end{array}$ & $\begin{array}{l}<0.0001 \\
<0.0001\end{array}$ \\
\hline
\end{tabular}

${ }^{\mathrm{a}-\mathrm{c}}$ Means in a row without a common letter differ, $P<0.05$.

${ }^{1}$ Control $=0 \mathrm{~m} M$ acetate and $0 \mathrm{n} M$ rapamycin; $\mathrm{R}=100 \mathrm{n} M$ rapamycin; $\mathrm{A}=6 \mathrm{~m} M$ acetate; $\mathrm{R}+\mathrm{A}=100 \mathrm{n} M$ rapamycin $+6 \mathrm{~m} M$ acetate; treatments were added to cultures for $48 \mathrm{~h}$. 
Table 5. Effect of acetate $(A)$ and rapamycin $(R)$ on the mRNA expression of genes involved in milk fat synthesis and mammalian target of rapamycin (mTOR) signaling pathway in bovine mammary epithelial cells

\begin{tabular}{|c|c|c|c|c|c|c|}
\hline \multirow[b]{2}{*}{ Gene } & \multicolumn{4}{|c|}{ Treatment $^{1}$} & \multirow[b]{2}{*}{ SEM } & \multirow{2}{*}{$\begin{array}{c}\text { Overall } \\
\text { treatment } \\
P \text {-value }\end{array}$} \\
\hline & Control & $\mathrm{R}$ & $\mathrm{A}$ & $\mathrm{R}+\mathrm{A}$ & & \\
\hline$F A S N$ & $1.00^{\mathrm{b}}$ & $0.63^{\mathrm{c}}$ & $1.62^{\mathrm{a}}$ & $0.64^{\mathrm{c}}$ & 0.028 & $<0.0001$ \\
\hline$A C A C A$ & $1.00^{\mathrm{b}}$ & $0.72^{\mathrm{c}}$ & $1.38^{\mathrm{a}}$ & $0.76^{\mathrm{c}}$ & 0.022 & $<0.0001$ \\
\hline$S C D 1$ & $1.00^{\mathrm{b}}$ & $0.79^{\mathrm{c}}$ & $1.47^{\mathrm{a}}$ & $0.78^{\mathrm{c}}$ & 0.008 & $<0.0001$ \\
\hline FABP3 & $1.00^{\mathrm{b}}$ & $0.20^{\mathrm{c}}$ & $2.18^{\mathrm{a}}$ & $0.28^{\mathrm{c}}$ & 0.016 & $<0.0001$ \\
\hline$L P L$ & 1.00 & 0.99 & 0.98 & 0.98 & 0.030 & 0.63 \\
\hline$P P A R G$ & $1.00^{\mathrm{b}}$ & $0.57^{\mathrm{c}}$ & $1.45^{\mathrm{a}}$ & $0.57^{\mathrm{c}}$ & 0.011 & $<0.0001$ \\
\hline$S R E B P 1$ & $1.00^{\mathrm{b}}$ & $0.52^{\mathrm{c}}$ & $1.87^{\mathrm{a}}$ & $0.56^{\mathrm{c}}$ & 0.022 & $<0.0001$ \\
\hline$m T O R$ & $1.00^{\mathrm{b}}$ & $0.73^{\mathrm{c}}$ & $1.53^{\mathrm{a}}$ & $0.79^{c}$ & 0.209 & $<0.0001$ \\
\hline$e I F 4 E$ & $1.00^{\mathrm{b}}$ & $0.52^{\mathrm{c}}$ & $1.87^{\mathrm{a}}$ & $0.89^{c}$ & 0.040 & $<0.0001$ \\
\hline $4 E B P 1$ & $1.00^{\mathrm{b}}$ & $0.64^{\mathrm{c}}$ & $1.68^{\mathrm{a}}$ & $0.71^{\mathrm{c}}$ & 0.080 & $<0.0001$ \\
\hline$S 6 K 1$ & $1.00^{\mathrm{b}}$ & $0.73^{\mathrm{c}}$ & $1.53^{\mathrm{a}}$ & $0.79^{c}$ & 0.130 & $<0.0001$ \\
\hline
\end{tabular}

${ }^{\mathrm{a}-\mathrm{c}}$ Means in a row without a common letter differ, $P<0.05$.

${ }^{1}$ Control $=0 \mathrm{~m} M$ acetate and $0 \mathrm{n} M$ rapamycin; $\mathrm{R}=100 \mathrm{n} M$ rapamycin; $\mathrm{A}=6 \mathrm{~m} M$ acetate; $\mathrm{R}+\mathrm{A}=100 \mathrm{n} M$ rapamycin $+6 \mathrm{~m} M$ acetate; treatments were added to cultures for $48 \mathrm{~h}$.

creased 74,72 , and $20 \%$ after transfection with eIF4E siRNA1, eIF4E siRNA2, and EIF4E siRNA3, respectively (Figure 2).

Compared with control, the eIF4E siRNA and acetate + eIF4E siRNA decreased RGR $(P<0.05)$, and acetate increased RGR $(P<0.05$; Table 6$)$. Acetate and acetate + eIF4E siRNA both increased TG synthesis $(P<0.05)$, but eIF4E siRNA had no effect on TG compared with control $(P>0.05$; Table 6$)$.

Compared with control, the expression of eIF $4 E$ was increased in acetate and decreased by $76 \%$ in eIF4E siRNA $(P<0.05$; Table 7$)$. The addition of acetate + eIF4E siRNA had no effect on eIF $4 E$ compared with eIF4E siRNA treatment $(P>0.05)$. The expression of

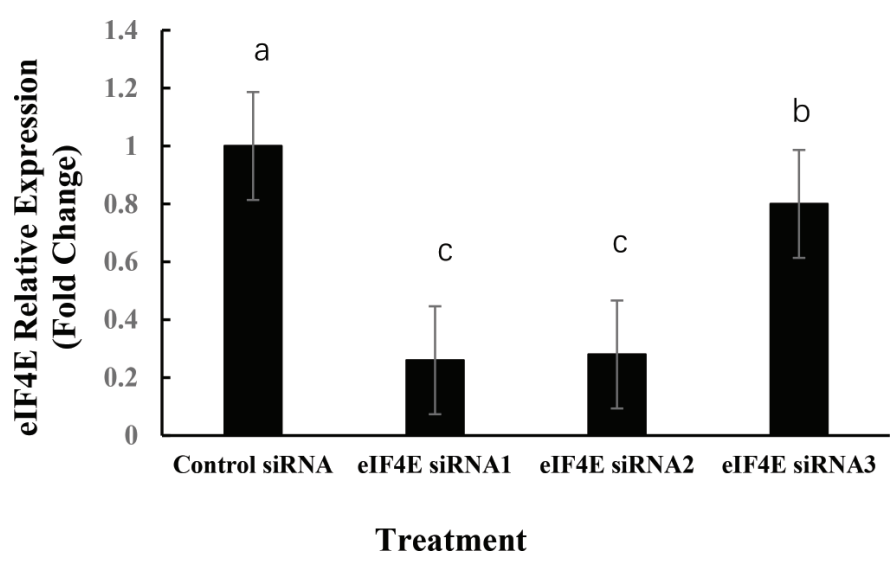

Figure 2. Effect of control small interfering (si)RNA or 1 of 3 eIF4E siRNA on mRNA expression of eIF $4 E$. Cells were harvested $24 \mathrm{~h}$ after transfection with control siRNA or 1 of 3 eIF4E siRNA to verify the mRNA expression of eIF4E. Compared with control, eIF $4 \mathrm{E}$ expression was decreased 74,72 , and $20 \%$, respectively, in the 3 eIF $4 \mathrm{E}$ siRNA. Values are presented as means \pm SEM. Different letters $(\mathrm{a}-\mathrm{c})$ represent significant differences $(P<0.05)$ in gene expression.
$4 E B P 1$ was higher in acetate than control and lower in eIF4E siRNA $(P<0.05)$. Also, the expression of $4 E B P 1$ in acetate + eIF4E siRNA treatment was lower than acetate, but higher than eIF4E siRNA $(P<0.05)$. The expression of mTOR and S6K1 did not differ between eIF4E siRNA and control, acetate, and acetate + eIF4E siRNA $(P>0.05)$, but was lower in eIF4E siRNA compared with control $(P<0.05$; Table 7$)$.

The expression of FASN, ACACA, SCD1, and SREBP1 was lower in eIF4E siRNA and acetate + eIF4E siRNA, and higher in acetate compared with control $(P<0.05)$. The expression of FASN, ACACA, and $S C D 1$ were higher in acetate + eIF4E siRNA than in eIF4E siRNA $(P<0.05$; Table 7$)$, and expression of $S R E B P 1$ did not differ between eIF4E siRNA and acetate + eIF4E siRNA $(P>0.05)$. The expression of $F A B P 3$ and PPARG was greater in acetate and acetate + eIF4E siRNA than in control, but did not differ between acetate and acetate + eIF4E siRNA, eIF4E siRNA, and control $(P>0.05)$. The expression of $L P L$ was not affected by acetate or eIF4E siRNA $(P>0.05)$.

\section{DISCUSSION}

\section{Effect of Different Concentrations of Acetate on Milk Fat Synthesis}

Milk fat is composed primarily of TG secreted from BMEC in variably sized droplets. Therefore, TG content directly reflects milk fat synthesis. In vitro results have shown that 8 to $20 \mathrm{mM}$ acetate results in greater TG in BMEC after $24 \mathrm{~h}$ of incubation (Kong et al., 2012), and TG content in BMEC is different in response to 10 $\mathrm{m} M$ acetate after 3 to $5 \mathrm{~d}$ of incubation compared with other treatments (Yonezawa et al., 2004). We observed similar results showing that TG content was regulated 
Table 6. Effect of acetate and eukaryotic initiation factor 4E (eIF4E) small interfering (si)RNA on relative growth rate (RGR) and triacylglycerol (TG, measured as optical density, OD) content in bovine mammary epithelial cells

\begin{tabular}{lcccccc}
\hline & \multicolumn{3}{c}{ Treatment $^{1}$} & & \\
\cline { 2 - 5 } Item & Control & eIF4E siRNA & Acetate $^{2}$ & Acetate + eIF4E siRNA & SEM \\
\hline RGR (\%) & $100.00^{\mathrm{b}}$ & $69.13^{\mathrm{d}}$ & $110.27^{\mathrm{a}}$ & $82.50^{\mathrm{c}}$ & 0.785 \\
TG (OD) & $0.109^{\mathrm{b}}$ & $0.107^{\mathrm{b}}$ & $0.122^{\mathrm{a}}$ & $0.121^{\mathrm{a}}$ & $<0.0001$ \\
\hline
\end{tabular}

${ }^{\mathrm{a}-\mathrm{d}}$ Means in a row without a common letter differ, $P<0.05$.

${ }^{1}$ Treatments: control $=$ cells cultured for $24 \mathrm{~h}$, and then in fresh medium for another $48 \mathrm{~h}$; eIF4E siRNA = cells cultured in medium with eIF4E siRNA for $24 \mathrm{~h}$ and then in medium for another $48 \mathrm{~h}$; acetate = cells cultured for $24 \mathrm{~h}$ and then in medium with 6 m $M$ acetate for $48 \mathrm{~h}$; acetate+eIF4E siRNA = cells cultured with eIF4E siRNA for $24 \mathrm{~h}$ and then cultured with acetate $(6 \mathrm{~m} M)$ for another $48 \mathrm{~h}$. Culture medium in all treatments was Dulbecco's modified Eagle's medium (DMEM)/F12 supplemented with 10\% fetal bovine serum.

by acetate in a dose-dependent manner in BMEC, but the underlying mechanism remained unclear. Therefore, our objective was to investigate the effect of acetate on the expression of genes related to milk fat synthesis.

The PPARG and SREBP1 genes are 2 important factors that regulate milk fat synthesis in mammary glands (Salter and Tarling, 2007). Kadegowda et al. (2008) demonstrated that genes related to de novo FA synthesis $(A C A C A, F A S N)$ and transcriptional regulation of lipid synthesis (SREBP1) were upregulated in MAC-T cells by treatment with a PPARG agonist. The $S R E B P 1$ gene positively regulates de novo FA synthesis $(A C A C A, F A S N)$, desaturation (SCD1), and intracellular FA trafficking (FABP3; Ma and Corl, 2012; Xu et al., 2016). These findings indicated that fat synthesis is regulated by $P P A R G$ and $S R E B P 1$. Our results showed that expression of these genes was greater when acetate was at 6 to $12 \mathrm{mM}$. Thus, the upregulation of $P P A R G$ and SREBP1 with acetate may have contributed to greater expression of genes related to de novo FA and long-chain FA trafficking and TG synthesis.
The $4 E B P 1, e I F 4 E$, and $S 6 K 1$ genes are currently the best-known downstream effectors of mTOR signaling. Studies indicated that PPARG and SREBP1 play an important role in mTOR signaling pathway regulating milk fat synthesis in the mouse model (Kim and Chen, 2004; Laplante et al., 2009). Inhibition of mTORC1 by rapamycin reduces accumulation of TG in 3T3-L1 adipocytes (Chakrabarti et al., 2010). Knockdown of eIF $E$ decreases protein expression of $S C D 1$ and $S R E B P 1$ in human mammary gland cancer cell (Luyimbazi et al., 2010), indicating that mTOR and eIF $4 E$ are involved in fatty acid synthesis. The present study found that the mTOR signaling pathway was activated by the addition of acetate in a dose-dependent manner. The relative expression of mTOR was increased by 20 to $68 \%$ with 4 to $6 \mathrm{mM}$ acetate, and decreased by 7 to $14 \%$ relative to control with 10 to $12 \mathrm{~m} M$ acetate. The relative expression of $4 E B P 1$ was higher in $6 \mathrm{~m} M$ acetate, and that of $e I F 4 E$ and $S 6 K 1$ was higher in 4 to $6 \mathrm{~m} M$ acetate. These results suggested that regulation of acetate on milk fat synthesis may be related to

Table 7. Effect of acetate and eukaryotic initiation factor 4E (eIF4E) small interfering (si)RNA on the mRNA expression of genes involved in milk fat synthesis and mTOR signaling pathway in bovine mammary epithelial cells

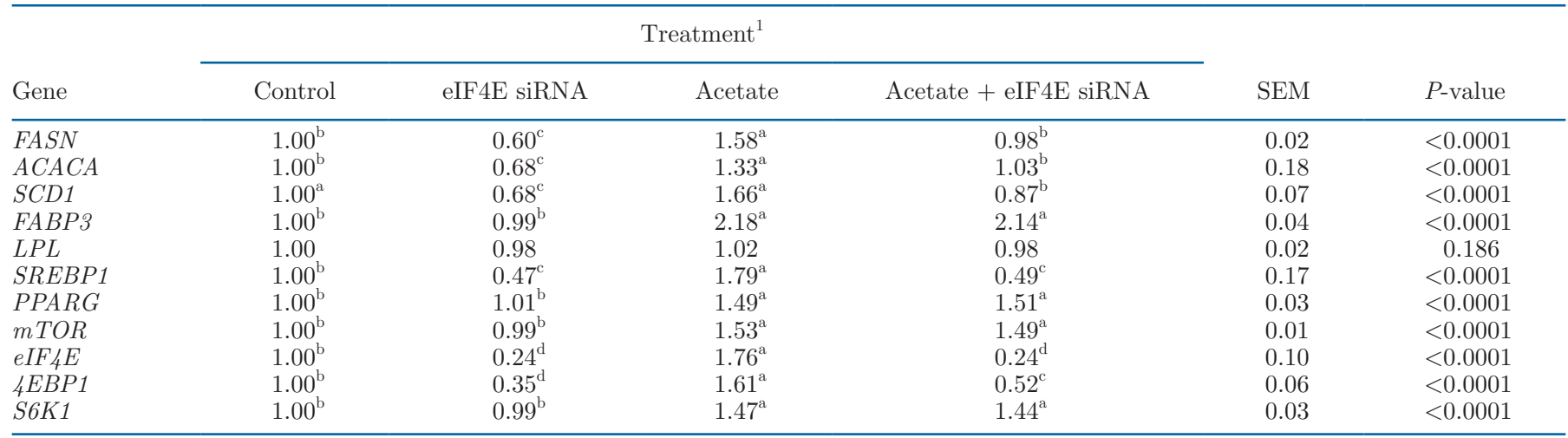

\footnotetext{
${ }^{\mathrm{a}-\mathrm{d}}$ Means in a row without a common letter differ, $P<0.05$.

${ }^{1}$ Treatments: control $=$ cells cultured for $24 \mathrm{~h}$, and then in fresh medium for another $48 \mathrm{~h}$; eIF4E siRNA = cells cultured in medium with eIF4E siRNA for $24 \mathrm{~h}$ and then in medium for another $48 \mathrm{~h}$; acetate $=$ cells cultured for $24 \mathrm{~h}$ and then in medium with $6 \mathrm{~m} M$ acetate for $48 \mathrm{~h}$; acetate+eIF4E siRNA = cells cultured with eIF4E siRNA for $24 \mathrm{~h}$ and then cultured with acetate $(6 \mathrm{~m} M)$ for another $48 \mathrm{~h}$. Culture medium in all treatments was Dulbecco's modified Eagle's medium (DMEM)/F12 supplemented with 10\% fetal bovine serum.
} 
the mTOR signaling pathway and that eIF4E was an important regulator. Acetate at 6 to $12 \mathrm{mM}$ increased expression of genes related to fatty acid synthesis, but 8 to $12 \mathrm{mM}$ acetate decreased expression of genes in the mTOR signaling pathway. Therefore, $6 \mathrm{mM}$ acetate was selected to investigate the mechanism of acetate regulating milk fat synthesis through the mTOR/eIF4E signaling pathway.

\section{Acetate Regulates Milk Fat Synthesis Through the mTOR/eIF4E Signaling Pathway}

The targeted siRNA that deceased eIF $4 E$ expression by 70 to $80 \%$ could be used for the experiment. Both eIF4E siRNA1 and eIF4E siRNA2 decreased eIF $4 E$ gene expression by 74 and $72 \%$, respectively. Therefore, both of these could be used to knock down eIF $4 E$ expression, and eIF4E siRNA1 was selected for the following experiment. The mTORC1 complex is the primary controller of cell growth (Burgos et al., 2010). Rapamycin, as a specific mTORC1 inhibitor, significantly inhibited growth in 3 breast cancer cell lines and showed a clinically achievable peak concentration in temsirolimus trials (Gangar et al., 2002; Fu et al., 2018). Knockdown of eIF4E has also been shown to suppress breast cancer cell growth (Zhou et al., 2011). We found that cell growth was increased by $6 \mathrm{mM}$ acetate, but it was decreased when mTOR was inhibited or eIF4E was knocked down. These results indicated that acetate regulated BMEC growth through the mTOR/eIF4E signaling pathway.

The PPARG and SREBP1 genes are key regulators in mTORC1 regulating milk fat synthesis in adipogenesis (Kim and Chen, 2004). Inhibition of the mTOR signaling pathway by rapamycin downregulates expression of SREBP1, ACACA, FASN, and SCD1 in mouse (Wang et al., 2011) and human mammary explants (Soliman, 2011), and PPARG activity in 3T3-L1 cells (Kim and Chen, 2004). The knockdown of eIF4E decreases transcription and translation of SCD1 and SREBP1, but phosphorylation of mTOR is not affected in human mammary gland cancer cells (Luyimbazi et al., 2010). We found similar results whereby rapamycin markedly suppressed the positive effect of acetate on gene expression of mTOR, eIF 4E, 4EBP1, S6K1, SREBP1, $P P A R G, A C A C A, F A S N$, and SCD1 in BMEC. The silencing of eIF4E suppressed the positive effect of acetate on expression of eIF $4 E, 4 E B P 1, S R E B P 1$, $A C A C A, F A S N, A C A C A$, and SCD1 in BMEC. However, gene expression of mTOR was not affected by silencing eIF4E. These findings indicated that eIF4E is an important regulator in fatty acid synthesis. Acetate regulates de novo synthesis and desaturation in BMEC through the mTOR/eIF4E signaling pathway, and SREBP1 may be the key regulator. Moreover, the up-regulation of acetate on FABP 3 expression was decreased by rapamycin, but did not respond to the silencing of eIF4E. Thus, the effect of acetate on intracellular long-chain FA trafficking was regulated by the mTOR signaling pathway without activating eIF4E. Although acetate regulated de novo synthesis and desaturation through the mTOR/eIF4E signaling pathway, TG was not regulated by knockdown of eIF4E. Bionaz and Loor (2008) found that once FA with $>10$ carbons are formed, they are activated by ACSL1 and bound to FABP3, which allows the FA to enter into the TAG synthesis. Therefore, TG synthesis did not respond to silencing of eIF4E, which may be related to FABP3.

\section{CONCLUSIONS}

Acetate increased milk fat synthesis in dose-dependent manner, and the mTOR/eIF4E signaling pathway plays an integral role in the regulation of acetate on milk fat synthesis and cell proliferation, and SPEBP1 may be an important regulation factor in BMEC.

\section{ACKNOWLEDGMENTS}

This research was supported by high-level talent start-up research project of Inner Mongolia Agriculture University (Project No. NDYB 2017-6) and national key basic research program of China (Project No. 2011CB1008003). The authors have not stated any conflicts of interest.

\section{REFERENCES}

Anderson, S. M., M. C. Rudolph, J. L. McManaman, and M. C. Neville. 2007. Secretory activation in the mammary gland: It's not just about milk protein synthesis! Breast Cancer Res. 9:204. https:// doi.org/10.1186/bcr1653.

Bauman, D. E., and J. M. Griinari. 2003. Nutritional regulation of milk fat synthesis. Annu. Rev. Nutr. 23:203-227. https://doi.org/ 10.1146/annurev.nutr.23.011702.073408.

Bionaz, M., and J. J. Loor. 2008. Gene networks driving bovine milk fat synthesis during the lactation cycle. BMC Genomics 9:366-387. https://doi.org/10.1186/1471-2164-9-366.

Burgos, S. A., M. Dai, and J. P. Cant. 2010. Nutrient availability and lactogenic hormones regulate mammary protein synthesis through the mammalian target of rapamycin signaling pathway. J. Dairy Sci. 93:153-161. https://doi.org/10.3168/jds.2009-2444.

Chakrabarti, P., T. English, J. Shi, C. M. Smas, and K. V. Kandror 2010. Mammalian target of rapamycin complex 1 suppresses lipolysis, stimulates lipogenesis, and promotes fat storage. Diabetes 59:775-781. https://doi.org/10.2337/db09-1602.

Efeyan, A., R. Zoncu, and D. M. Sabatini. 2012. Amino acids and mTORC1: From lysosomes to disease. Trends Mol. Med. 18:524533. https://doi.org/10.1016/j.molmed.2012.05.007.

Fu, J.-H., S. Yang, C.-J. Nan, C.-C. Zhou, D.-Q. Lu, S. Li, and H.-Q. $\mathrm{Mu}$. 2018. Mir-182 affects renal cancer cell proliferation, apoptosis, and invasion by regulating PIK3/AKT/mTOR signaling pathway. Eur. Rev. Med. Pharmacol. Sci. 22:351-357. https://doi.org/10 .26355/eurrev_201801_14179. 
Gangar, A., S. Raychaudhuri, and R. Rajasekharan. 2002. Alteration in the cytosolic triacylglycerol biosynthetic machinery leads to decreased cell growth and triacylglycerol synthesis in oleaginous yeast. Biochem. J. 365:577-589. https://doi.org/10.1042/ bj20011654.

Guertin, D. A., and D. M. Sabatini. 2007. Defining the role of mTOR in cancer. Cancer Cell 12:9-22. https://doi.org/10.1016/j.ccr.2007 .05 .008 .

Jacobs, A. A. A., J. Dijkstra, J. S. Liesman, M. J. VandeHaar, A. L. Lock, A. M. van Vuuren, W. H. Hendriks, and J. van Baal. 2013. Effects of short- and long-chain fatty acids on the expression of stearoyl-CoA desaturase and other lipogenic genes in bovine mammary epithelial cells. Animal 7:1508-1516. https://doi.org/10 $.1017 /$ S175173111300061X.

Kadegowda, A. K. G., M. Bionaz, L. S. Piperova, R. A. Erdman, and J. J. Loor. 2008. Lipogenic gene expression in MAC-T cells is affected differently by fatty acids and enhanced by PPAR-gamma activation. J. Anim. Sci. 86(E-Suppl.):566.

Kim, J. E., and J. Chen. 2004. Regulation of peroxisome proliferatoractivated receptor-gamma activity by mammalian target of rapamycin and amino acids in adipogenesis. Diabetes 53:2748-2756. https://doi.org/10.2337/diabetes.53.11.2748.

Kong, Q. Y., Y. Lin, and L. I. Qing-Zhang. 2012. Influence on breast fatty acid biosynthesis related genes with sodium acetate and sodium butyrate. Chinese Dairy Industry. 40:15-17.

Lamming, D. W., and D. M. Sabatini. 2013. A central role for mTOR in lipid homeostasis. Cell Metab. 18:465-469. https://doi.org/10 .1016/j.cmet.2013.08.002.

Laplante, M., and D. M. Sabatini. 2012. mTOR signaling in growth control and disease. Cell 149:274-293. https://doi.org/10.1016/j .cell.2012.03.017.

Livak, K. J., and T. D. Schmittgen. 2001. Analysis of relative gene expression data using real-time quantitative PCR and the $2^{-\Delta \Delta C}$ method. Methods 25:402-408. https://doi.org/10.1006/meth.2001 .1262 .

Luyimbazi, D., A. Akcakanat, P. F. McAuliffe, L. Zhang, G. Singh, A. M. Gonzalez-Angulo, H. Chen, K. A. Do, Y. Zheng, M. C. Hung, G. B. Mills, and F. Meric-Bernstam. 2010. Rapamycin regulates stearoyl CoA desaturase 1 expression in breast cancer. Mol. Cancer Ther. 9:2770-2784. https://doi.org/10.1158/1535-7163.MCT $-09-0980$.

Ma, L., and B. A. Corl. 2012. Transcriptional regulation of lipid synthesis in bovine mammary epithelial cells by sterol regulatory element binding protein-1. J. Dairy Sci. 95:3743-3755. https://doi .org/10.3168/jds.2011-5083.

Maxin, G., F. Glasser, C. Hurtaud, J. L. Peyraud, and H. Rulquin. 2011. Combined effects of trans-10, cis-12 conjugated linoleic acid, propionate, and acetate on milk fat yield and composition in dairy cows. J. Dairy Sci. 94:2051-2059. https://doi.org/10.3168/jds.2010 -3844 .
Oh, W. J., and E. Jacinto. 2011. mTOR complex 2 signaling and functions. Cell Cycle 10:2305-2316. https://doi.org/10.4161/cc.10 .14 .16586 .

Ramirez-Zacarias, J. L., F. Castro-Munozledo, and W. Kuri-Harcuch. 1992. Quantitation of adipose conversion and triglycerides by staining intracytoplasmic lipids with Oil red O. Histochemistry 97:493-497. https://doi.org/10.1007/bf00316069.

Salter, A. M., and E. J. Tarling. 2007. Regulation of gene transcription by fatty acids. Animal 1:1314-1320. https://doi.org/10.1017/ S1751731107000675.

Sheng, R., S. M. Yan, L. Z. Qi, Y. L. Zhao, L. Jin, and X. Y. Guo. 2016. Effect of the ratios of acetate and $\beta$-hydroxybutyrate on the expression of milk fat- and protein-related genes in bovine mammary epithelial cells. Czech J. Anim. Sci. 60:531-541. https://doi .org/10.17221/8595-CJAS.

Soliman, G. A. 2011. The integral role of mTOR in lipid metabolism. Cell Cycle 10:861-862. https://doi.org/10.4161/cc.10.6.14930.

Urrutia, N. L., and K. J. Harvatine. 2017. Acetate dose-dependently stimulates milk fat synthesis in lactating dairy cows. J. Nutr. 147:763-769. https://doi.org/10.3945/jn.116.245001.

Wang, B. T., G. S. Ducker, A. J. Barczak, R. Barbeau, D. J. Erle, and K. M. Shokat. 2011. The mammalian target of rapamycin regulates cholesterol biosynthetic gene expression and exhibits a rapamycin-resistant transcriptional profile. Proc. Natl. Acad. Sci. USA 108:15201-15206. https://doi.org/10.1073/pnas.1103746108.

Xu, H. F., J. Luo, W. S. Zhao, Y. C. Yang, H. B. Tian, H. B. Shi, and M. Bionaz. 2016. Overexpression of srebp1 (sterol regulatory element binding protein 1) promotes de novo fatty acid synthesis and triacylglycerol accumulation in goat mammary epithelial cells. J. Dairy Sci. 99:783-795. https://doi.org/10.3168/jds.2015-9736.

Yonezawa, T., S. Yonekura, M. Sanosaka, A. Hagino, K. Katoh, and Y. Obara. 2004. Octanoate stimulates cytosolic triacylglycerol accumulation and CD36 mRNA expression but inhibits acetyl coenzyme A carboxylase activity in primary cultured bovine mammary epithelial cells. J. Dairy Res. 71:398-404. https://doi.org/10.1017/ S0022029904000408.

Zhou, F. F., M. Yan, G. F. Guo, F. Wang, H. J. Qiu, F. M. Zheng, Y. Zhang, Q. Liu, X. F. Zhu, and L. P. Xia. 2011. Knockdown of eIF4E suppresses cell growth and migration, enhances chemosensitivity and correlates with increase in Bax/Bcl-2 ratio in triplenegative breast cancer cells. Med. Oncol. 28:1302-1307. https:// doi.org/10.1007/s12032-010-9630-0.

\section{ORCIDS}

Yanli Zhao 으 https://orcid.org/0000-0002-8709-9634 Sumei Yan ( 1 https://orcid.org/0000-0002-4107-2858 Binlin Shi ๑ https://orcid.org/0000-0002-8550-3509 